Article

\title{
Editing Cumulated Landscapes: Point Cloud Modeling as a Method of Analysis in Landscape Design
}

\author{
Philipp R. W. Urech ${ }^{1,2}$ \\ ${ }^{1}$ Future Cities Laboratory, Singapore-ETH Centre, 138602 Singapore; Singapore \\ ${ }^{2}$ Chair of Landscape Architecture of Prof. Christophe Girot, ETH Zurich, 8092 Zurich, Switzerland; \\ E-Mail: urech@arch.ethz.ch
}

Submitted: 10 February 2020 | Accepted: 5 May 2020 | Published: 30 June 2020

\begin{abstract}
Pragmatic planning juxtaposed with conflicting agendas has led to metropolitan territories with little quality for urban life. Rapidly growing urban agglomeration, synchronous with the Great Acceleration of the global society, is causing massive landscape change leading to radical breaks with traditional landscapes. By drawing from the formal properties of the environment that include existing qualities, it is possible to develop solutions that respond to both a broader and more specific context. The method resorts to laser scanning technology to produce three-dimensional point cloud models and use them as a prospective medium to perform informed transformations in the landscape. Laser-scanned 3D models can help take advantage of subtle topographic differences to support water management, capture significant site features, and provide an accurate site inventory that could reduce the cost of displaced terrain and replanted trees. The article discusses how point cloud models can support the site investigation as part of a digital design method in the field of landscape design. The approach engages formal characteristics of a physical landscape and results in a transformative workflow linked to the survey and the analysis of the site. By using modes of visualization and coloring to emphasize shapes, densities, and heights, the model can reveal relevant landscape features and patterns that are otherwise not noticeable. Section 1 introduces the methods used in other disciplines; Section 2 provides explanations about how the methods apply to a case study in landscape design; Section 3 presents the possibilities offered by the approach to integrate formal characteristics of the environment during the design process. Design development based on documented features in the point cloud model increases the control to shape environments that contribute to the process of accumulation occurring in the landscape.
\end{abstract}

\section{Keywords}

change detection; digital landscape design; geometric analysis; geometric documentation; point cloud modeling

\section{Issue}

This article is part of the issue "Territories in Time: Mapping Palimpsest Horizons" edited by Chiara Cavalieri (UCLouvain, Belgium) and Elena Cogato Lanza (EPFL, Switzerland).

(C) 2020 by the author; licensee Cogitatio (Lisbon, Portugal). This article is licensed under a Creative Commons Attribution 4.0 International License (CC BY).

\section{Introduction}

The perpetual transformation of landscapes by the people who inhabit them constitutes a fundamental characteristic in the morphology of the landscape. The idea that anthropogenic activities shape the environment promoted the concept of cultural landscapes (Sauer, 1925). Cultural landscapes embody a historical accumulation and, with the growth of societies, evolved to become specialized landscapes at large scale (Conzen, 2001). The continuous adaptation of cultural development to the changing conditions of terrestrial dynamics has called for more holistic views that blend the dualism of natural and artificial landscape formation (Ingold, 1993).

The cartographic view of the environment influences the temporal perception of landscape transformation. Attempts to include imprints of time were explored with the layering of geologic maps that lead to a prospective use of overlay maps in landscape design (Berrizbeitia, 2014). At the same time, the cartographic representation 
of the territory weakened the understanding of space, which regressed to a flat and set concept (Massey, 2005, p. 28). In reality, the process of accumulation occurring in the landscape is a diachronic process that continues to form the land (Corboz, 1983). The analogy of the palimpsest describes the process of progressive erasure and overwriting that forms a place by comparing it to partially-erased writings that have been covered by a new one. The analogy explains the phenomenon of accumulation, but it does not specify the relation that may exist between accumulated residues of older landscape forms. The entanglement physically manifested in architectural palimpsests is more likely the result of a succession of preconditioned states (Ooijen, 2019). Like architectural palimpsests in which residues of old forms are absorbed in the new layout of walls, residues of the former site configuration become part of the transformed landscape.

Any design aimed at transforming the landscape contributes to an ongoing accumulation of environmental and anthropogenic changes. It is hence useful to explore how the accumulation, physically manifested in landscape forms, can be addressed during a design process. In the context of urban renewal, the transformation of a site ensues from an assessment followed by particular decisions on preservation or replacement (Lynch, 1976, pp. 29-41). In the field of landscape design, a similar relation to the environment calls for specific management of site characteristics. Consequently, information is collected by surveys to undertake landscape analysis that encompasses parametric, areal, and historical approaches (Stahlschmidt, Nellemann, Primdahl, \& Swaffield, 2017). Landscape analyses use generic modes of representation to study the physical configuration of the landscape and often fall short of addressing specific forms of landscape features, such as the varied vegetation of a grove, the form of a rocky riverbed, and the feeble but consequential human alterations to the environment. The capacity to document the landscape form influences the decision of which landscape features are to be included or removed in the design. The absence of specificity when giving form to a new landscape during the design process results in a conceptual break between form and information. The methods of geometric documentation and geometric analysis with 3D models open the possibility to include accumulated properties of a site in the design process.

\subsection{Geometric Documentation}

Various disciplines indirectly analyze an object or a site using geometric documentation. The approach, also referred to as geometric recording, consists in producing a digital 3D replica based on measures. It is used in heritage conservation to register the position and the shape of monuments at a particular moment in time and helps to provide necessary information for inventory and research (International Committee of Architectural
Photogrammetry, 1972). A range of acquisition tools for surface measures enables the production of 3D geometric records (Georgopoulos \& Stathopoulou, 2017). Laserscanning technology can be combined with photogrammetry to document the form of heritage sites such as historical pavements (Martínez, Ortiz, \& Gil, 2015), heritage monuments (Bariami, Faka, Georgopoulos, loannides, \& Skarlatos, 2012), and large-scale historical settlements (von Schwerin et al., 2016). The approach applies to other fields that require measured 3D models to investigate the form of objects, such as monitoring tunnel excavations (Gikas, 2012) and measuring topographic surface change (Lague, Brodu, \& Leroux, 2013).

The quality of 3D models produced for geometric documentation depends on the occlusion, the precision, and the resolution of the measures, prompting to select the appropriate tool to acquire the object of study (Boardman \& Bryan, 2018). The survey of complex environments such as tiered vegetation and urban landscapes has experienced a leap in definition with laserscanning technology that acquires surface measures at a long range and penetrates porous geometries. Airborne laser scanning measures the land cover with multiple returns and simultaneously reaches and documents the ground (Liu, 2008). The technology has thus been useful to reveal marks left by the passage of time in largescale landscapes (Mlekuž, 2013). Meanwhile, in the context of landscape planning, small topographic differences can have severe implications for land management. For this reason, institutes carry out scanning missions on a regional scale for purposes such as to assess the flood risk in the Philippines (Blanco, Tamondong, Perez, Ang, \& Paringit, 2015), to monitor water flow and dikes in the Netherlands (Nationaal Georegister Netherlands, 2007, 2014), and to supervise coastal areas in the United States (Davidson \& Miglarese, 2003).

\subsection{Geometric Analysis}

The 3D geometric record of a site enables an indirect analysis of its geometry. Laser-scanned geometry in the form of point cloud models can be analyzed to classify and separate terrain points from vegetation, buildings, and unconventional types of geometry (von Schwerin et al., 2016). A detailed analysis distinguishes geomorphological elements based on their geometric properties across multiple scales (Brodu \& Lague, 2012). Once filtered, the bare geometry of the terrain can be visualized by elevation or by local relief shadings to emphasize meaningful features (Chase, Chase, Fisher, Leisz, \& Weishampel, 2012; Evans et al., 2013; Hesse, 2010). The vegetation geometry in point cloud models provides the assessment of the habitat structure for animal species diversity (Simonson, Allen, \& Coomes, 2014), the separation of vegetation clusters (Cabo, Ordóñez, García-Cortés, \& Martínez, 2014; Cabo, Ordóñez, López-Sánchez, \& Armesto, 2018), and volume estimation of individual trees (Lefsky \& McHale, 2008). 
In addition to inspecting the geometric characteristics of point cloud models, the geometric comparison of datasets recorded at different intervals can determine how much the site has changed in time (Mukupa, Roberts, Hancock, \& Al-Manasir, 2017; Okyay, Telling, Glennie, \& Dietrich, 2019). The precision of change detection depends on the data quality of the 3D model (Kromer et al., 2015) and implies high standards for producing geometric documentation, since noise such as irregular surfaces recorded by photogrammetry may introduce errors (Du et al., 2016; Stal, Tack, Maeyer, Wulf, \& Goossens, 2013). Detecting the change in the canopy profile can indicate the growth rate of forests ( $Y u$, Hyyppä, Kukko, Maltamo, \& Kaartinen, 2006) and variations in the complex topography of landslides (Lague et al., 2013). For the analyses on both shape and change, a majority of studies will rather work with projected and filtered data such as digital elevation models. However, the data translation, the low sensitivity, and the one-dimensional comparison of changes could lead to a potential loss of information (Mukupa et al., 2017).

\section{Methods}

It is becoming common practice for designers to personally collect spatial data of the site with the support of laser scanning devices (Rekittke, Ninsalam, \& Paar, 2015). The modeling process, based on the ability to collect, append, densify, and update data from the site, offers the possibility to develop a holistic understanding of the space (Pirokka, Ellis, \& del Tredici, 2015). In the context of urban landscapes, such understanding is necessary to mend modern cities that were fragmented, among other things, by functionalist planning practices (Girot, 2006). Geometric documentation of the environment offers clues to past and ongoing events occurring in the landscape. In studies on archaeological landscapes, largescale data acquisition by airborne laser scanning provides information to explain how anthropogenic transformations and constructions appear in the terrain. The vegetation layer, of little interest for such studies, is therefore filtered out (Doneus \& Briese, 2011). In contrast, a project development in landscape design encompasses the complete physical form of the site in transformation, including features of varying kinds and duration.

\subsection{Geometric Documentation of the Environment}

The physical form of the landscape can be separated in two principal categories that are the landformtopographic shapes from small-scale ditches and slopes to large-scale riverbeds and valleys-and the land cover-from grasses, shrubs and fences to forests, power lines, and buildings. Consequently, the survey with laser scanning technology aims at producing 3D geometric documentation of both categories and must be planned accordingly to ensure that features are recorded with an adequate extent and point density (Boardman \& Bryan,
2018, pp. 44-53). For the use of point cloud models in landscape design, the minimum distance between points should ideally be about $25 \mathrm{~cm}$ to distinguish smaller objects, such as fences and light poles, and detailed forms, like the vegetation structure and steps in the ground. High-density datasets like the aerial laser-scan of the city of Dublin (Laefer et al., 2013) provide detailed documentation of both the topography and the form of the aboveground urban inventory but are very rare. However, surveys with aerial laser scanning are occurring in an evergrowing number of regions and have densities of $50 \mathrm{~cm}$ or less between points, which already provides a useful definition for large-scale landscape design. In locations where these datasets are not available or are of low density, terrestrial laser scanning can be used to produce the missing information. The survey with terrestrial laser-scanners might be an arduous and time-consuming operation, depending on the extent and the complexity of the site, which must be scanned piece by piece from strategically defined positions to reduce occlusions. The resulting datasets are then registered together with algorithms such as the Iterative Closest Point (Besl \& McKay, 1992) to form a continuous topology of surface measures. Practical procedures are described in various literature (Boardman \& Bryan, 2018; Crutchley \& Crow, 2018; Vincent, Bendicho, loannides, \& Levy, 2017).

To be used as a 3D model for geometric documentation, raw laser-scanned data requires a basic preparation that includes the removal of noise and the registration of overlapping scan sources. Noise, moving objects, and imprecise registration could trigger false positives during geometrical change detection. The quality of point cloud models, determinant for the analysis of geometrical features, is commonly affected by scanning procedures such as a high angle of incidence (Boardman \& Bryan, 2018, pp. 26-30). Especially in the case of nearground terrestrial laser-scanning, the radial point distribution combined with a grazing incidence to the terrain will affect the point density significantly at an increasing distance. The geometric documentation as a 3D point cloud model is a representation of the present form of the landscape, as natural processes and human activities have shaped it over time.

\subsection{Geometric Analysis of Landscape Features}

The analysis of the geometric documentation is useful to highlight features of the point cloud model. The analysis requires a point cloud model with a sufficiently dense and continuous point distribution to support the identification of geometric features. Visual documentation with laser scanning might appear very similar to geometric documentation when they are compared in the right perspective. However, shown in a planar view, the visual documentation omits information essential to reveal the accumulated characteristics of the landscape, such as the depression left by the former railway passing below the road intersection (see Figure 1). Missing data has to be 
(a)

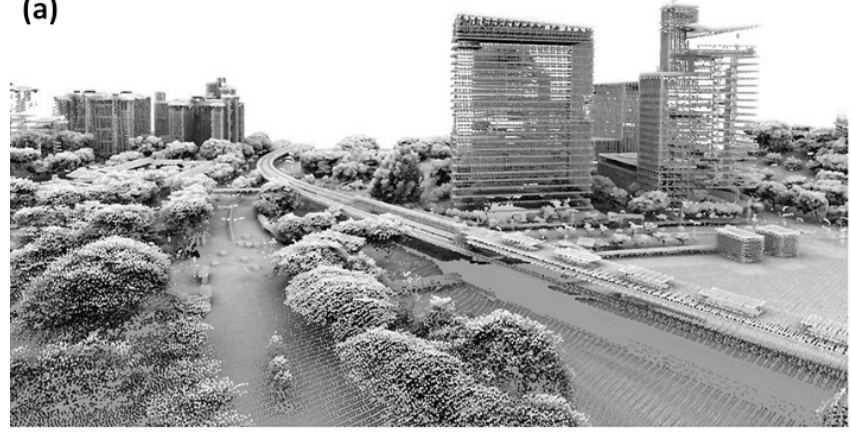

(b)

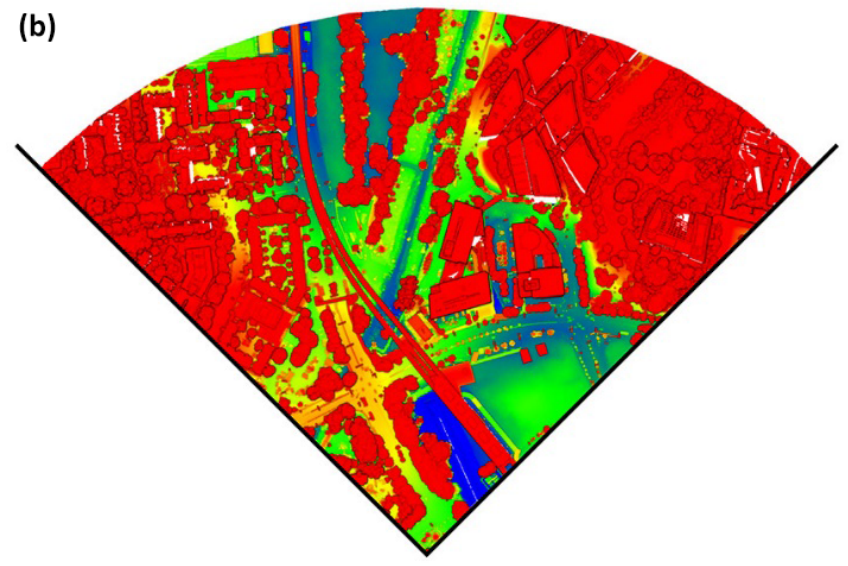

(c)

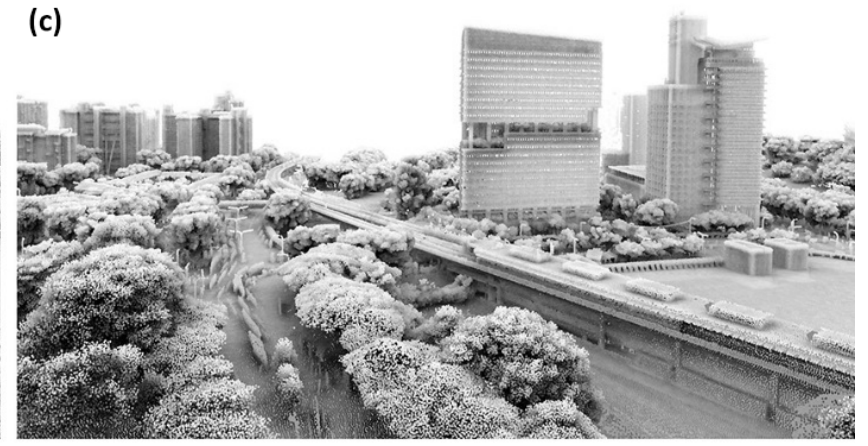

(d)

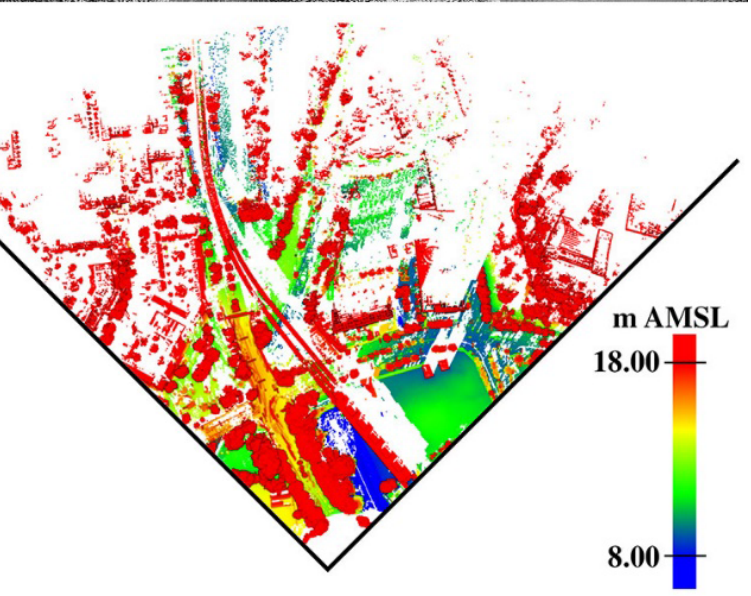

Figure 1. Geometric and visual documentation of a landscape near the Buona Vista station in Singapore. The point cloud models were recorded with aerial $(a, b)$ and terrestrial $(c, d)$ laser scanners. Data combined from three terrestrial scanning locations on rooftops close to the viewpoint of the perspective (c), are suitable for visualization purposes and resemble the perspective view with the aerial data (a). Explicit in plan view, there is insufficient information on features relevant to landscape design, as the topography is mostly occluded and trees are scanned on one side only (d). There are fewer occlusions during aerial laser scanning, which only needs to penetrate about $30 \mathrm{~m}$ of vegetation height to document the vertical structure and canopy (b).

compensated by combining different scanning locations. This process can be expensive and time-consuming for large-scale landscapes with a high amount of occlusions to cover and with locations sometimes difficult to access.

Geometric features are displayed on point cloud models with scalar values. Each point can store scalar values based on the laser pulse-e.g., the intensity and the number of returns - or based on the scanning procedure, such as the scan direction and scan angle (ASPRS, 2019, Version 1.4-R15). A further type of scalar values can be computed from the geometric analysis of point cloud models. For example, the elevation of the model can be computed along the Z-axis to visually emphasize details otherwise difficult to notice (e.g., Mlekuž, 2013). The elevation can also be calculated relative to the distance of a reference object such as the topography, as it is the case for calculating the height above the ground of the tree canopy (e.g., Yu et al., 2006). To compute the height of objects, the ground needs first to be identified as such, which can be done with classification algorithms (e.g., Uysal \& Polat, 2014; Zhang et al., 2016). The classification of ground points is necessary to expose the topography and analyze its geometric properties.

\subsection{Geometric Change Detection in Landscape Transformations}

The method of geometric change detection is used to show how a design physically implemented in the landscape is manifested in a 3D model. The result indicates how 3D point cloud models can be manipulated for prospective use in landscape design to operate a physical transformation between two moments in time. A pair of point cloud models recorded at different times on the same site is compared geometrically with a fine registration and a distance calculation, both performed in this case with the processing software Cloud Compare (Girardeau-Montaut, 2019). Occlusions and unequal extents may cause the analysis to detect false positives. Therefore, the compared point cloud models must have an equivalent coverage area and point density. First, the point cloud models have to be precisely aligned using the fine registration that is applied through a rigid body transformation (Besl \& McKay, 1992; Rusinkiewicz \& Levoy, 2001). One model is taken as a reference and remains in position while the algorithm minimizes the point-topoint distances of the second model iteratively by apply- 
ing translations and rotations. After a successful registration, one model is again taken as the reference, and a distance calculation is computed in relation to the second point cloud model. The distance calculation is saved as a new scalar field displayed on the geometry of the compared point cloud model. Adapting the threshold of the scalar field highlights the geometry that has changed more than a given distance. It is worth noting that the comparison is meaningful only when applied to comparable geometries. If buildings have replaced trees, the distance comparison between the two models will show that parts of the buildings look wrongly unchanged as they coincide with the former position of trees. Features need therefore to be separated by classification, as explained in the previous section, before comparing the distance separately for topographic, vegetal, and built features.

The geometric change detection applied to comparable features helps to evaluate physical changes to the landform and land cover. The transformation of Fort Vechten by Jonathan Penne Architects and West8 illus- trates how a design implementation influences the landscape. The project, completed in 2016 near Utrecht, transforms the historical fort to include the National Waterline Museum. The comparison of two aerial laserscans of the Netherlands by the Dutch register reveals to what degree the topography and the land cover of the former fort were transformed (Nationaal Georegister Netherlands, 2007, 2014). The aerial laserscanned data already included classification and geolocation. The scalar fields based on the distance between the geometries revealed changes applied with great attention to the slopes of the fort and the trees (see Figure 2).

The transformations visible in the laser-scanned model coincide with specific design intentions. A $90 \mathrm{~m}$ $\times 450 \mathrm{~m}$ cut in the vegetation, not fully completed at the time of the second scan, was being made to reveal the former look of the bare military earthwork. The topographic modifications restored the deteriorated earthwork according to the original fort design. A new car park has been leveled for visitors at the new north-east entrance of the fort. Excavated terrain was moved west to
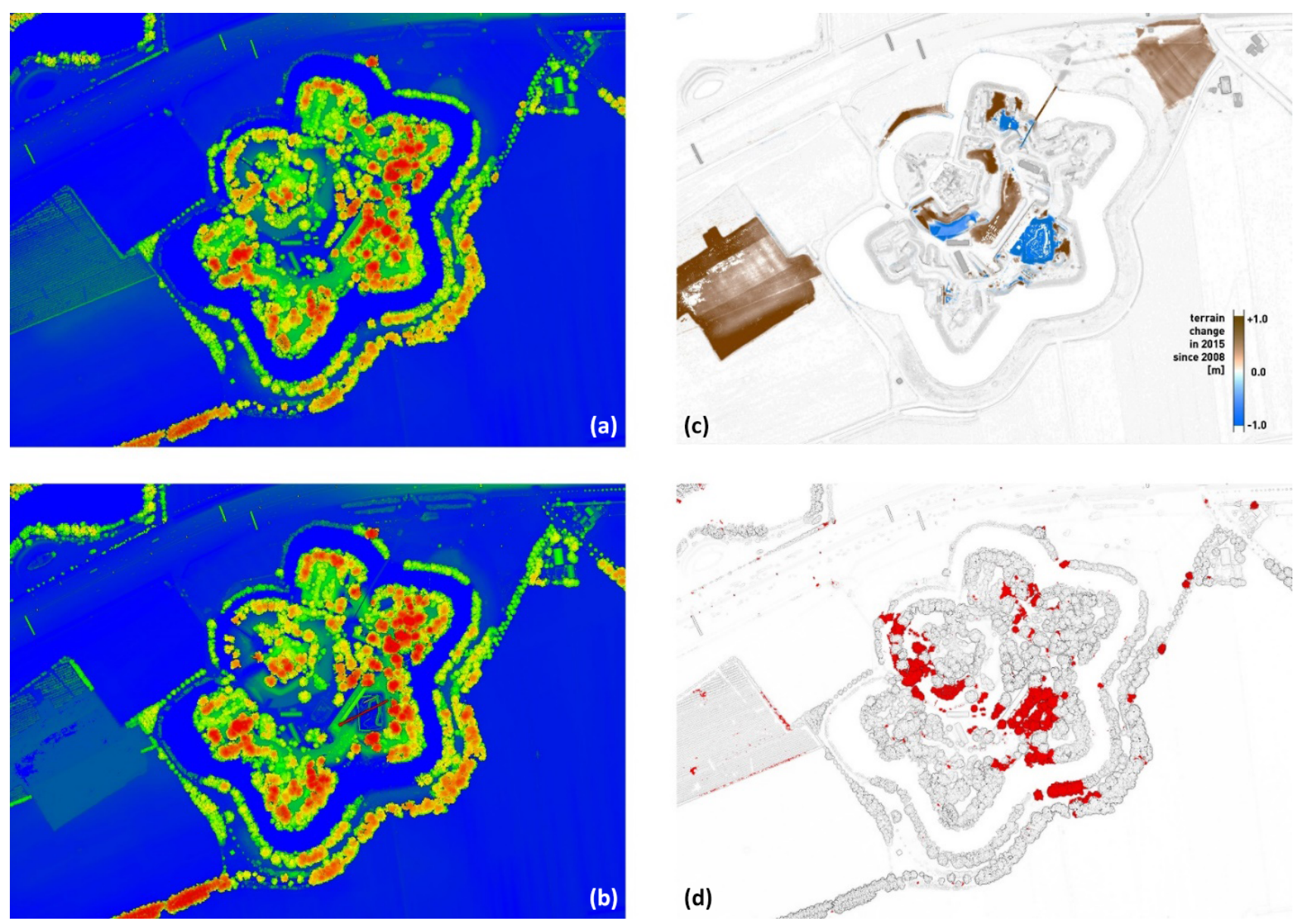

Figure 2. Change detection between point cloud models shows a landscape design implemented at Fort Vechten, in the Netherlands. The two models, shown in plan view, were produced from the aerial laser scanning data collected by the Dutch government in 2008 (a) and 2015 (b) and are colored by height (0-30 m AMSL). A geometric change detection, performed on ground points only, highlights the terrain volume that has been added or subtracted by $1 \mathrm{~m}$ height or more on the 2015 point cloud model (c). The distance calculation of $2 \mathrm{~m}$ or more highlights the trees removed since the 2008 record (d). 
a nearby field to minimize the transportation costs and later partly reused, as confirmed by the designers. The change detection between several geometric records shows how a point cloud model can be modified to correspond to physical changes. The design process involves a prospective use of the 3D model that goes beyond the descriptive role of point cloud models representing a set moment in time.

\subsection{Application in Landscape Design}

Methods of geometric documentation and analysis were applied during a design studio. This section illustrates how the methods presented above are used for design investigation by following specific steps (see Figure 3 ). The assignment consisted in developing the open space along a former railway crossing the island of Singapore to mitigate the urban heat with new landscape configurations. Design development relied exclusively on the medium of point cloud models. The first two steps consist in acquiring laser-scanned data and preparing it as a model. Data personally collected from rooftops surrounding the railway with a long-range terrestrial laser scanner was registered onto the georeferenced airborne laser-scanned data from the government (Singapore Land Authority, 2014). The datasets (see Figure 1) were then cleaned from atmospheric noise and moving objects for the geometric documentation of existing topography and vegetation structure. The colors of the aerial dataset were interpolated in 3D from the terrestrial dataset or projected in 2D from aerial images, where the former was missing. The resulting 3D point cloud model was made available to the studio in the form of LAZ files (Isenburg, 2013) and on the visualization platform Potree (Schuetz, 2016). Geometric documentation visualized in three dimensions provided us with a base to understand landscape forms and to inspect details during studio discussions, such as the water drainage of a plot or probable breezeways in the existing vegetation. The platform enabled us to visualize transects and to take measures in real-time (Scheiblauer, 2014). The transects expose spatial correlations of landscape features and were used to systemically extract sections through the model. Measures were taken to determine the size of the road and water infrastructure and to investigate the flow direction in water channels with minimal inclination.

The next step consists of geometric analysis. The visualization of elevation values enabled different observations by changing the threshold of the scalar field. Students were able to highlight landforms too large, complex, or subtle to grasp, such as the graded hillsides of the Kent Ridge, the drainage network near the Alexandra hospital, and the traces of a former railway junction in Bukit Timah. Although we received the aerial data with the classification of ground, vegetation, and built objects, the quality of the terrestrial dataset was found to be inadequate for classification as extensive occlusions of the terrain (see Figure 1) would have led to misinterpretations. Using Cloud Compare, the analysis of geometric properties was therefore only performed on the aerial dataset, since the computation of height above ground, planarity and normal orientation requires geometric documentation with a continuous point distribution and the classification of ground points.

In the last step, analysis of the geometry allows us to disassemble point cloud models. Due to their particle structure, the models are well-suited for segmentation based on sections, classifications, filtering, and manual segmentation. The scalar values computed from the geometric analysis allow us to perform selective segmentation and extract chosen portions of the existing landscape. The scalar values are filtered by their range and enable the disassembly of the model in geometrically defined groups. In this way, we could integrate and configure useful landscape features anew during the ensuing modeling process.

\section{Results}

Although it is difficult to assess the influence that the methods have on all decisions made during the design process, the geometric change detection allows us to compare the laser-scanned models of the site and the manipulated point cloud models produced

\begin{tabular}{|c|c|c|c|c|c|c|c|}
\hline Methods & SURVEY & & $\begin{array}{l}\text { GEOMETRIC } \\
\text { DOCUMENTATION }\end{array}$ & & $\begin{array}{l}\text { GEOMETRIC } \\
\text { ANALYSIS }\end{array}$ & & SEGMENTATION \\
\hline $\begin{array}{r}\text { Modeling } \\
\text { taks }\end{array}$ & $\begin{array}{l}\text { Data aquisition } \\
\text { - laser scanning } \\
\text { - image aquisition } \\
\text { - image calibration }\end{array}$ & $>$ & $\begin{array}{l}\text { Model } \\
\text { preparation } \\
\text { - registration } \\
\text { - georeferencing } \\
\text { - cleaning } \\
\text { - color projection }\end{array}$ & $>$ & $\begin{array}{l}\text { Model analysis } \\
\text { - elevation } \\
\text { - classification } \\
\text { - compute distance } \\
\text { - compute geometric } \\
\text { features }\end{array}$ & $>$ & $\begin{array}{l}\text { Disassembly } \\
\text { - filtering } \\
\text { - manual } \\
\text { segmentation } \\
\text { - label connected } \\
\text { components }\end{array}$ \\
\hline $\begin{array}{r}\text { Resulting } \\
\text { datasets }\end{array}$ & $\begin{array}{l}\text { Laser-scanned } \\
\text { raw data }\end{array}$ & & 3D point cloud model & & $\begin{array}{l}\text { 3D point cloud model } \\
\text { with scalar values }\end{array}$ & & $\begin{array}{l}\text { Segmented parts of } \\
\text { point cloud models }\end{array}$ \\
\hline
\end{tabular}

Figure 3. Steps to use laser-scanned data as a source for geometric documentation and analysis for an investigative purpose in landscape design. 
at the end of the studio. The geometric change detection reveals landscape transformations envisioned through manipulated point cloud models (see Figure 4). The comparison highlights a series of approaches that carefully manage site characteristics by keeping selected features in their georeferenced position. The approaches can be distinguished between landform and land cover transformations.

Landform transformations have three different approaches to handle existing topography. The approaches consist of an extensive alteration, a selective replacement, and the preservation of existing landforms. First, an extensive alteration of landforms occurs through the change of more than $30 \mathrm{~cm}$ in height to the terrain surface, e.g., modeled in Rhinoceros 3D (McNeel, 2018, Version 6.0). Despite the high degree of change that may alter the perception of the site, this transformation is not a tabula rasa since it evolves from the existing topography taken as the starting point for the manipulation. This approach applies to the case of the canal south of Alexandra Hospital, whose engineered edges were reshaped into a soft topography (see Figure 4). The altered landform is always connected seamlessly to the unchanged topography. Second, a selective replacement of landforms involves the interweaving of topographic changes with the existing terrain. The example of Fort Vechten (see Figure 2) shows that landform transformations, being expensive, can be strictly local, and yet result in significant changes. A similar approach took place in the Wessex area along the railway, where the elevated topography, occupied by former military barracks, was segmented by elevation to be conserved. Third, many areas of the manipulated point cloud models preserve existing landforms. However, depending on the surface treatment, these landforms have not necessarily remained intact. For example, scraping them clean of vegetation by using classification values required smoothing their surface to make them aesthetically pleasing. This approach provided the opportunity to retain portions of the graded slopes, reminiscent of the former railway, by filtering out high dip values computed through the normal orientation of ground points.

Land cover transformations offer two approaches for addressing existing vegetation and buildings, either by using them as a context for adding features or transforming them through the selective removal of features. First, the contextual addition consists of inserting landscape features within the existing context. Visual appreciation of the point cloud model provides the basis for identifying potential open spaces that can be developed by adding features, leading us to make important decisions early in the design process. This approach worked for the conversion of a temporary parking lot (upperright corner of Figure 4a) into a buffer park with newlyplanted trees between Queensway road and Alexandra Hospital. The second approach is a selective removal of land cover features, which is a costly and incisive operation for the identity of the site and therefore needs careful planning. The selective removal involves identifying specific features and removing them in the point cloud model. Topographic transformations inevitably lead to the removal of existing trees. The removal of land cover points above the transformed topography is achieved by computing the cloud-to-cloud distance between the scanned and manipulated terrain, then using the distance values interpolated on the land cover to remove the affected points. This semi-automatic operation is complemented by manual segmentations to correct irregularities. The approach was used to selectively remove vegetation near the corrected edge of the canal after the topography was altered (see Figure $4 \mathrm{~b}$ ). In other instances, where land cover remains unaffected by landform transformations, visual appreciation and geometric analysis of the point cloud model assessed the inclu-
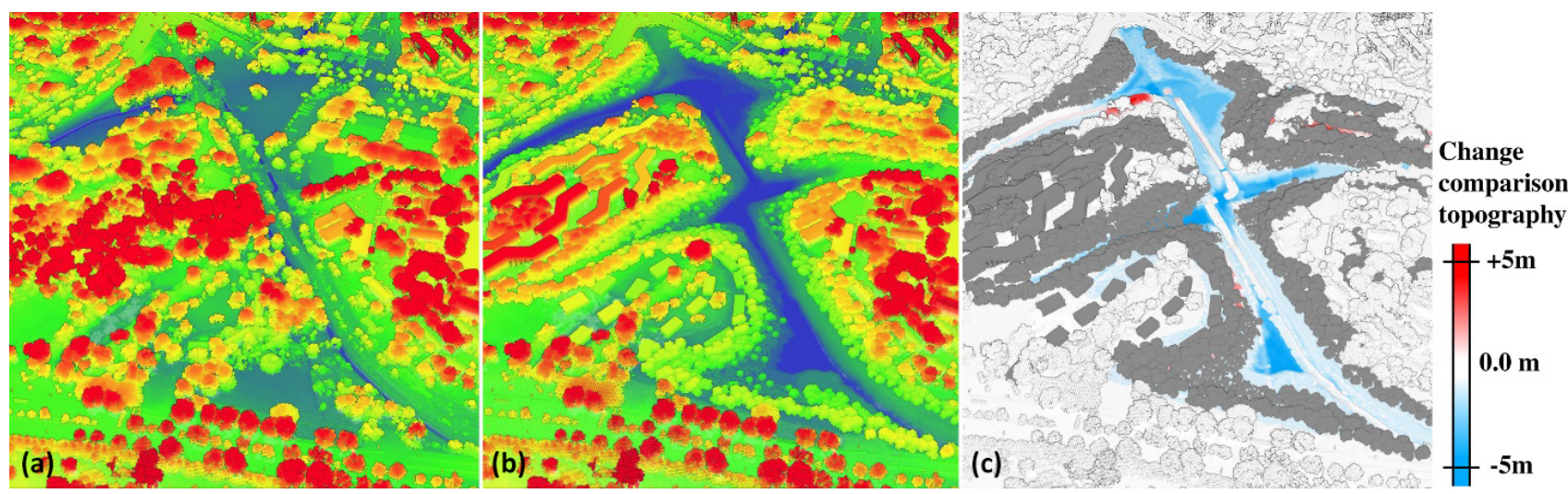

Figure 4. Change detection between laser-scanned and modified point cloud models. A point cloud model from aerial laserscanned data, colored by height 3-40 m AMSL, shows a $3 \mathrm{~m}$-wide canal (in dark blue) aligned to the former railway (a). The point cloud model is manipulated to improve the capacity of water catchment, shown with the same height gradient (b). The design maintains the original depth of the canal and height of the railway, both colored in white in the topographic change comparison (c). The comparison shows how existing features can be retained locally during the design process, while changes occur in less-significant parts. 
sion of existing land cover features. Geometric analysis, like the height above ground, has facilitated the identification of vegetation patterns and possible heritage trees worthy of integration. Tall trees were extracted from the vegetation points by applying a threshold to height-above-ground values and by computing the cloudto-cloud distance between the canopy above the threshold and the remaining points to extract the base of the trees. This semi-automatic operation required segmentation by hand or by label-connected components to correct probable errors. This approach was useful to identify potential breezeways oriented in the predominant wind direction, across the railway corridor, and to develop them by selectively removing existing trees and buildings (see Figure 4b).

This set of approaches for the landform and the land cover allowed us to make conscious decisions about how to include or transform existing site characteristics that contribute to the accumulation process of the landscape. The approaches were combined in different forms during the design process, resulting in the development of spatially complex solutions, such as the use of existing flyover bridges over transformed topography and the rearranging the vegetation over an existing drainage system.

\section{Conclusion}

As a discipline of spatial transformation, landscape design has the task of responding to the context in which it operates. It is therefore relevant to integrate sitespecific knowledge into the design process from the outset. Landscape change has important consequences for the site, which are sometimes so abrupt that they leave holes in the cultural imprint of the land (Corboz, 1983). Vast urbanization combined with unconcerned planning policies has provoked irreversible breaks with traditional landscapes (Antrop, 2005). As with any planned landscape transformation, even contextually weak designs must respond to the reality of the site, at the latest when they are implemented on the terrain. Although some features of import to the identity of the site may disappear in the course of careless operations, others will eventually prevail over design schemes that have not taken them into account. Modern cities are so young that they have not yet absorbed the long-term dynamics inherent in the landscape, confronting them with increasingly recurring consequences such as floods and urban heat islands.

Although all the landscape design methods currently in use result in the physical transformation of a site, only a few approaches allow us to take a stance on the accumulation that characterizes a site. Technological advances provide deeper insight to understand the accumulation and refine our observations. Digital Elevation models may provide important information on large-scale landscape change, like topographic transformations for land reclamation in Singapore (Wang, Belle, \& Hassler, 2015), but are not sufficient to explain the mutual rela- tion between landforms and land cover. Geometric documentation in point cloud models, on the other hand, enables the cultivation of a relationship to the full form of the landscape from the early stages of design. Informed choices for shaping the site can respond to the underlying morphology of the landscape, avoiding contradictory operations. Features revealed by the geometric analysis of point cloud models still require a knowledge of interpretation, also necessary in the identification of archaeological traces (Johnson \& Ouimet, 2018). Although the distinction between landform and land cover can be effectively made with software such as Lastools (Isenburg \& Shewchuk, 2019), advanced multi-scale classification could strengthen analysis and modeling capabilities for landscape design (Brodu \& Lague, 2012; Yang, Dong, Zhao, \& Dai, 2015). Semantics are still in their infancy and remain difficult to implement systematically on largescale landscapes.

From a spatial point of view, landscape designs can extend horizontally over many kilometers but are vertically limited to a few dozen meters above and below existing topography. For this reason, the planarity of maps is often considered sufficient to provide information on changing landscape configurations. Considering a large river like the Mekong on a map does not suggest that it flows in a curve around the curvature of the earth, contained by small topographic variations that cause it to reverse its flow in some segments during a monsoon. Temporal phenomena on a large scale such as flooding, sealevel rise, forest fires, and thermal radiation are determined specifically from the physical landscape structure along the elevation axis and call for adequate attention. The temporal dimension of point cloud models seems to form a contradiction since landscapes are changing while models are continuous (Davis, 2015). But the passage of time is imprinted in the landscape palimpsest, physically formed by processes at multiple scales of time and space. Working with geometric documentation increases the sensitivity and criterion for site-specific design. A design process informed by point cloud models can move central decisions regarding the implementation of a landscape project from the construction phase to the development phase. The application of laser-scanning technology in landscape design opens the possibility of handling the environment as a constructed interlinkage of parts that has different durations and has evolved gradually. In the end, the investigation for landscape design could be less the reading of a palimpsest than it could be the taphonomy of a diachronic construct.

\section{Acknowledgments}

I would like to thank Professor Christophe Girot, Professor Joshua Comaroff and teaching assistants Magdalena Kaufmann, Benedikt Kowalewski, Fujan Fahmi, Dennis Häusler for the collaboration on the Design Research Studio of the Rail Corridor in Singapore. I also would like to thank Professor Andreas Georgopoulos for his 
references on geometric documentation and architect Penne Hangelbroek for his kind explanations about his project at Fort Vechten. This research was conducted at the Future Cities Laboratory, Singapore-ETH Centre, which was established collaboratively between ETH Zurich and Singapore's National Research Foundation (FI 370074011) under its Campus for Research Excellence and Technological Enterprise Programme.

\section{Conflict of Interests}

The author declares no conflict of interest.

\section{References}

Antrop, M. (2005). Why landscapes of the past are important for the future. Landscape and Urban Planning, 70(1), 21-34. https://doi.org/10.1016/j.landurbplan. 2003.10.002

ASPRS. (2019). LAS specification [File Format]. Retrieved from https://github.com/ASPRSorg/LAS

Bariami, G., Faka, M., Georgopoulos, A., loannides, M., \& Skarlatos, D. (2012). Documenting a UNESCO world heritage site in Cyprus with complementary techniques. International Journal of Heritage in the Digital Era, 1(Suppl. 1), 27-32. https://doi.org/10.1260/ 2047-4970.1.0.27

Berrizbeitia, A. (2014). Between deep and ephemeral time: Representations of geology and temporality in Charles Eliot's Metropolitan Park system, Boston (1892-1893). Studies in the History of Gardens \& Designed Landscapes, 34(1), 38-51. https://doi.org/ 10.1080/14601176.2013.850295

Besl, P. J., \& McKay, N. D. (1992). Method for registration of 3-D shapes. Sensor Fusion IV: Control Paradigms and Data Structures, 1611, 586-606. https://doi.org/ 10.1117/12.57955

Blanco, A. C., Tamondong, A. M., Perez, A. M. C., Ang, M. R. C. O., \& Paringit, E. C. (2015). The Phil- LiDAR 2 program: National resource inventory of the Philippines using LiDAR and other remotely sensed data. ISPRS-International Archives of the Photogrammetry, Remote Sensing and Spatial Information Sciences, 7, 1123-1127. https://doi.org/ 10.5194/isprsarchives-XL-7-W3-1123-2015

Boardman, C., \& Bryan, P. (2018). 3D laser scanning for heritage: Advice and guidance on the use of laser scanning in archaeology and architecture (3rd ed.). Swindon: Historic England.

Brodu, N., \& Lague, D. (2012). 3D terrestrial LiDAR data classification of complex natural scenes using a multi-scale dimensionality criterion: Applications in geomorphology. ISPRS Journal of Photogrammetry and Remote Sensing, 68, 121-134. https://doi.org/ 10.1016/j.isprsjprs.2012.01.006

Cabo, C., Ordóñez, C., García-Cortés, S., \& Martínez, J. (2014). An algorithm for automatic detection of polelike street furniture objects from Mobile Laser Scan- ner point clouds. ISPRS Journal of Photogrammetry and Remote Sensing, 87, 47-56. https://doi.org/ 10.1016/j.isprsjprs.2013.10.008

Cabo, C., Ordóñez, C., López-Sánchez, C. A., \& Armesto, J. (2018). Automatic dendrometry: Tree detection, tree height and diameter estimation using terrestrial laser scanning. International Journal of Applied Earth Observation and Geoinformation, 69, 164-174. https:// doi.org/10.1016/j.jag.2018.01.011

Chase, A. F., Chase, D. Z., Fisher, C. T., Leisz, S. J., \& Weishampel, J. F. (2012). Geospatial revolution and remote sensing LiDAR in Mesoamerican archaeology. Proceedings of the National Academy of Sciences, 109(32), 12916-12921. https://doi.org/ $10.1073 /$ pnas.1205198109

Conzen, M. P. (2001). Cultural landscape in geography. In N. J. Smelser \& P. B. Baltes (Eds.), International encyclopedia of the social \& behavioral sciences (pp. 3086-3092). Oxford: Pergamon. https://doi.org/ 10.1016/B0-08-043076-7/02543-2

Corboz, A. (1983). The land as palimpsest. Diogenes, 121, 12-34.

Crutchley, S., \& Crow, P. (2018). Using airborne LiDAR in archaeological survey: The light fantastic. Swindon: Historic England.

Davidson, M. A., \& Miglarese, A. H. (2003). Digital coast and the national map: A seamless cooperative. Photogrammetric Engineering and Remote Sensing, 69(10), 1127-1131.

Davis, B. (2015). Landscapes of math. Kerb: Journal of Landscape Architecture, 23, 38-43.

Doneus, M., \& Briese, C. (2011). Airborne Laser Scanning in forested areas: Potential and limitations of an archaeological prospection technique. In D. C. Cowley (Ed.), Remote sensing for archaeological heritage management: Proceedings of the 11th EAC heritage management symposium (pp. 59-76). Brussels: Europae Archaeologiae Consilium.

Du, S., Zhang, Y., Qin, R., Yang, Z., Zou, Z., Tang, Y., \& Fan, C. (2016). Building change detection using old aerial images and new LiDAR data. Remote Sensing, 8(12). https://doi.org/10.3390/rs8121030

Evans, D. H., Fletcher, R. J., Pottier, C., Chevance, J.B., Soutif, D., Tan, B. S., . . Boornazian, G. (2013). Uncovering archaeological landscapes at Angkor using LiDAR. Proceedings of the National Academy of Sciences, 110(31), 12595-12600. https://doi.org/ $10.1073 /$ pnas. 1306539110

Georgopoulos, A., \& Stathopoulou, E. K. (2017). Data acquisition for 3D geometric recording: State of the art and recent innovations. In M. L. Vincent, V. M. Bendicho, M. loannides, \& T. E. Levy (Eds.), Heritage and archaeology in the digital age: Acquisition, curation, and dissemination of spatial cultural heritage data (pp. 1-26). Cham: Springer International Publishing. https://doi.org/10.1007/978-3-319-65370-9

Gikas, V. (2012). Three-dimensional laser scanning for geometry documentation and construction manage- 
ment of highway tunnels during excavation. Sensors, 12(8), 11249-11270. https://doi.org/10.3390/ s120811249

Girardeau-Montaut, D. (2019). 3D point cloud and mesh processing software (Version 2.10.1). Cloud Compare. Retrieved from www.danielgm.net/cc

Girot, C. (2006). Vision in motion: Representing landscape in time. In C. Waldheim (Ed.), The landscape urbanism reader (pp. 87-103). New York, NY: Princeton Architectural Press.

Hesse, R. (2010). LiDAR-derived local relief models: A new tool for archaeological prospection. Archaeological Prospection, 17(2), 67-72. https://doi.org/ 10.1002/arp.374

Ingold, T. (1993). The temporality of the landscape. World Archaeology, 25(2), 152-174. https://doi.org/ 10.1080/00438243.1993.9980235

International Committee of Architectural Photogrammetry. (1972). Photogrammetry applied to the survey of historic monuments, of sites, and to archeology. Paris: ICOMOS.

Isenburg, M. (2013). LASzip: Lossless compression of LiDAR data. Photogrammetric Engineering and Remote Sensing, 79(2), 209-217.

Isenburg, M., \& Shewchuk, J. (2019). Converting, viewing and compressing LIDAR data in LAS format. LAStools. https://rapidlasso.com

Johnson, K. M., \& Ouimet, W. B. (2018). An observational and theoretical framework for interpreting the landscape palimpsest through airborne LiDAR. Applied Geography, 91, 32-44. https://doi.org/ 10.1016/j.apgeog.2017.12.018

Kromer, R. A., Abellán, A., Hutchinson, D. J., Lato, M., Edwards, T., \& Jaboyedoff, M. (2015). A 4D filtering and calibration technique for small-scale point cloud change detection with a terrestrial laser scanner. Remote Sensing, 7(10), 13029-13052. https://doi.org/ 10.3390/rs71013029

Laefer, D. L., O'Sullivan, C., Carr, H., Truong-Hong, L., Science Foundation Ireland, Environmental Protection Agency, Fugro Airborne Surveys, \& University College Dublin. (2013). Aerial laser scanning (ALS) data collected over an area of around 1 square $\mathrm{km}$ in Dublin city in 2007 [Data set]. Dublin: UCD Library, University College Dublin Library. http://dx.doi.org/ 10.7925/drs1.ucdlib_30462

Lague, D., Brodu, N., \& Leroux, J. (2013). Accurate 3D comparison of complex topography with terrestrial laser scanner: Application to the Rangitikei canyon (N-Z). ISPRS Journal of Photogrammetry and Remote Sensing, 82, 10-26. https://doi.org/10.1016/ j.isprsjprs.2013.04.009

Lefsky, M. A., \& McHale, M. R. (2008). Volume estimates of trees with complex architecture from terrestrial laser scanning. Journal of Applied Remote Sensing, 2(1). https://doi.org/10.1117/1.2939008

Liu, X. (2008). Airborne LiDAR for DEM generation: Some critical issues. Progress in Physical Geography: Earth and Environment, 32(1), 31-49. https://doi.org/ 10.1177/0309133308089496

Lynch, K. (1976). What time is this place? Cambridge, MA: MIT Press.

Martínez, S., Ortiz, J., \& Gil, M. (2015). Geometric documentation of historical pavements using automated digital photogrammetry and high-density reconstruction algorithms. Journal of Archaeological Science, 53, 1-11. https://doi.org/10.1016/j.jas.2014.10.003

Massey, D. B. (2005). For space. New York, NY: Sage Publications.

McNeel, R. (2018). Rhinoceros 3D [3D Computer Graphics Software]. Retrieved from www.rhino3d.com

Mlekuž, D. (2013). Messy landscapes: LiDAR and the practices of landscaping. In R. S. Opitz \& D. C. Cowley (Eds.), Interpreting archaeological topography: Airbone laser scanning, 3d data and ground observation (pp. 88-99). Oxford: Oxford Books.

Mukupa, W., Roberts, G. W., Hancock, C. M., \& AlManasir, K. (2017). A review of the use of terrestrial laser scanning application for change detection and deformation monitoring of structures. Survey Review, 49(353), 99-116. https://doi.org/10.1080/00396265. 2015.1133039

Nationaal Georegister Netherlands. (2007). AHN2 Actueel Hoogtebestand Nederland [Current Dutch elevation; Data set]. Actueel Hoogtebestand Nederland. Retrieved from https://www.ahn.nl

Nationaal Georegister Netherlands. (2014). AHN3 Actueel Hoogtebestand Nederland [Current Dutch elevation; Data set]. Actueel Hoogtebestand Nederland. Retrieved from https://www.ahn.nl

Okyay, U., Telling, J., Glennie, C. L., \& Dietrich, W. E. (2019). Airborne LiDAR change detection: An overview of Earth sciences applications. EarthScience Reviews, 198. https://doi.org/10.1016/ j.earscirev.2019.102929

Ooijen, J. V. (2019). Resilient matters: The cathedral of Syracuse as an architectural palimpsest. Architectural Histories, 7(1). https://doi.org/10.5334/ah.65

Pirokka, M., Ellis, E., \& del Tredici, P. (2015). Personal remote sensing: Computer vision landscapes. New Geographies 07, 7, 178-187.

Rekittke, J., Ninsalam, Y., \& Paar, P. (2015). Using massive field data for large-size design action. In E. Buhmann, S. M. Ervin, \& M. Pietsch (Eds), Peer reviewed proceedings of digital landscape architecture 2015 (pp. 318-327). Berlin: Wichmann.

Rusinkiewicz, S., \& Levoy, M. (2001). Efficient variants of the ICP algorithm. D. C. Young (Ed.), Third international conference on 3-D digital imaging and modeling proceedings (pp. 145-152). Piscataway, NJ: IEEE Xplore. https://doi.org/10.1109/IM.2001.924423

Sauer, C. O. (1925). The morphology of landscape. In C. O. Sauer (Ed.), University of California Publications in Geography (Vol. 2, pp. 19-53). Berkeley, CA: University of California Press.

Scheiblauer, C. (2014). Interactions with gigantic point 
clouds (Unpublished Doctoral Dissertation). Vienna University of Technology, Vienna, Austria.

Schuetz, M. (2016). Potree: Rendering large point clouds in web browsers (Unpublished Doctoral Dissertation). Vienna University of Technology, Vienna, Austria.

Simonson, W. D., Allen, H. D., \& Coomes, D. A. (2014). Applications of airborne LiDAR for the assessment of animal species diversity. Methods in Ecology and Evolution, 5(8), 719-729. https://doi.org/10.1111/2041210X.12219

Singapore Land Authority. (2014). 2014 aerial LiDAR of Singapore [Data set]. Singapore: Singapore Land Authority.

Stahlschmidt, P., Nellemann, V., Primdahl, J., \& Swaffield, S. (2017). Landscape analysis: Investigating the potentials of space and place. Abingdon: Routledge.

Stal, C., Tack, F., Maeyer, P. D., Wulf, A. D., \& Goossens, R. (2013). Airborne photogrammetry and LiDAR for DSM extraction and 3D change detection over an urban area: A comparative study. International Journal of Remote Sensing, 34(4), 1087-1110. https://doi. org/10.1080/01431161.2012.717183

Uysal, M., \& Polat, N. (2014). Investigating performance of airborne LiDAR data filtering with triangular irregular network (TIN) algorithm. ISPRSInternational Archives of the Photogrammetry, Remote Sensing and Spatial Information Sciences, 40(7), 199-202. https://doi.org/10.5194/isprsarchives-XL7-199-2014

Vincent, M. L., Bendicho, V. M. L.-M., loannides, M., \& Levy, T. E. (Eds.). (2017). Heritage and archaeol- ogy in the digital age: Acquisition, curation, and dissemination of spatial cultural heritage data. Cham: Springer International Publishing. https://doi.org/ 10.1007/978-3-319-65370-9

von Schwerin, J., Richards-Rissetto, H., Remondino, F., Spera, M. G., Auer, M., Billen, N., . . . Reindel, M. (2016). Airborne LiDAR acquisition, post-processing and accuracy-checking for a 3D WebGIS of Copan, Honduras. Journal of Archaeological Science: Reports, 5, 85-104. https://doi.org/10.1016/j.jasrep.2015.11. 005

Wang, T., Belle, I., \& Hassler, U. (2015). Modelling of Singapore's topographic transformation based on DEMs. Geomorphology, 231, 367-375. https://doi.org/ 10.1016/j.geomorph.2014.12.027

Yang, B., Dong, Z., Zhao, G., \& Dai, W. (2015). Hierarchical extraction of urban objects from mobile laser scanning data. ISPRS Journal of Photogrammetry and Remote Sensing, 99, 45-57. https://doi.org/10.1016/ j.isprsjprs.2014.10.005

Yu, X., Hyyppä, J., Kukko, A., Maltamo, M., \& Kaartinen, H. (2006). Change detection techniques for canopy height growth measurements using airborne laser scanner data. Photogrammetric Engineering \& Remote Sensing, 72(12), 1339-1348. https://doi.org/ 10.14358/PERS.72.12.1339

Zhang, W., Qi, J., Wan, P., Wang, H., Xie, D., Wang, X., \& Yan, G. (2016). An easy-to-use airborne LiDAR data filtering method based on cloth simulation. Remote Sensing, 8, 501. https://doi.org/10.3390/rs8060501

\section{About the Author}

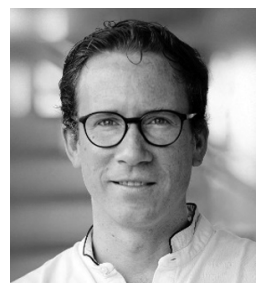

Philipp R. W. Urech is a Swiss Architect. Since 2010 he has been a Research Associate at the chair of Landscape Architecture of Professor Christophe Girot at the ETH Zurich. He was a Guest Lecturer at the Technion in Haifa, at the Singapore University of Technology and Design (SUTD) and the National University of Singapore (NUS). Since 2017 he has conducted doctoral research at the Future Cities Laboratory in Singapore on design methods that integrate the physical geometry of the environment. 